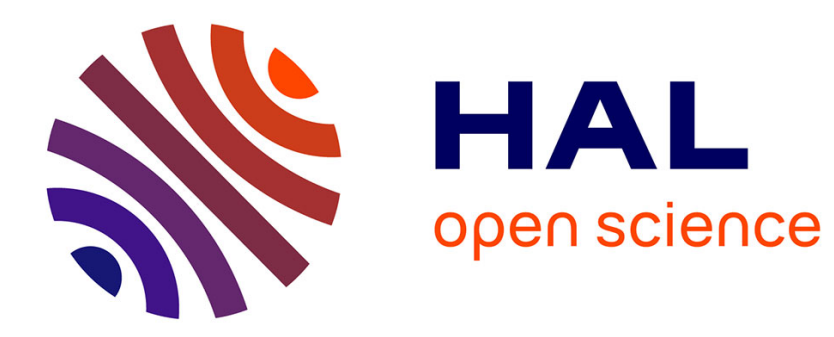

\title{
Portfolio choice with time horizon risk
}

Alexis Direr

\section{To cite this version:}

Alexis Direr. Portfolio choice with time horizon risk. 2020. hal-02879759

\section{HAL Id: hal-02879759 \\ https://hal.science/hal-02879759}

Preprint submitted on 24 Jun 2020

HAL is a multi-disciplinary open access archive for the deposit and dissemination of scientific research documents, whether they are published or not. The documents may come from teaching and research institutions in France or abroad, or from public or private research centers.
L'archive ouverte pluridisciplinaire HAL, est destinée au dépôt et à la diffusion de documents scientifiques de niveau recherche, publiés ou non, émanant des établissements d'enseignement et de recherche français ou étrangers, des laboratoires publics ou privés. 


\title{
Portfolio choice with time horizon risk
}

\author{
Alexis Direr *
}

June 24, 2020

\begin{abstract}
I study the allocation problem of investors who hold their portfolio until a target wealth is attained. The strategy suppresses final wealth uncertainty but creates an investment time horizon risk. I begin with a simple mean variance model transposed in the duration domain, then study a dynamic portfolio choice problem with Generalized Expected Discounted Utility preferences. Using long-term US return data, I show in the mean variance model that a large amount of time horizon risk can be diversified away by investing a significant share of equities. In the dynamic model, more impatient investors are also more averse to timing risk and invest less in equities. The equity share is downward trending with accumulated wealth relative to its target.
\end{abstract} J.E.L. codes: D8, E21

Keywords : portfolio choice, risk aversion, timing risk

*Univ. Orléans, LEO. E-mail: alexis.direr@univ-orleans.fr. ORCiD: 0000-0002-4459-7780. 


\section{Introduction}

Many households invest in financial markets with a personal goal in mind, like saving for retirement, buying a home or planning to help financially their children or grand-parents. Financial goals with an explicit wealth target takes an uncertain time to be attained, depending on market performance and volatility. The uncertainty may suit investors who prefer waiting to missing their target. For instance, people who undergo financial losses may choose deferring the purchase of a new car or their retirement date. When feasible or affordable, setting a flexible time horizon can be an effective risk management policy. By doing so, investors escape final wealth risk but face in exchange a time horizon (or duration) risk. A target wealth combined with a flexible time horizon have fundamental consequences for the way investors trade-off risk and return in financial markets. By investing in equities rather than fixed income assets, investors may expect a shorter delay but also a riskier investment time interval.

In this article I study a two-asset portfolio choice problem of an investor who sets a money goal and waits until it is attained. Investors are impatient and prefer a shorter time horizon all else equal. Based on experimental evidence (Onay and Öncüler, 2007, Dejarnette et al., 2020), I assume that investors are averse to timing risk, i.e. prefer to meet their target wealth in a sure date than in a random date with equal expected delay. Moreover, when faced with two non-degenerate mean preserving date distributions, they prefer the less risky one.

I find that the traditional risk-return trade-off faced by investors in the wealth domain does not transpose identically in the duration domain. Using annual return data on US equity and short-term bonds (commercial papers and certificates of deposits) between 1871 and 2019, I present five stylized facts about 
the comparative benefits of money market assets and equities in terms of expected duration and duration risk. Since bills generate less return on average, they impose longer durations than equities to attain a given wealth level. More surprisingly, they are also riskier than equities in terms of duration variance and skewness. I then present a simple CAPM-like portfolio choice model in which investors have mean variance preferences over uncertain investment durations. Based on long-period return statistics, I show that a large amount of duration risk can be diversified away by buying sufficient equities.

Last, I study a dynamic and microfounded model of portfolio choice. Investors compose their portfolio with two assets. The first one is more profitable in expectation and more risky than the second one. The trade-off between expected duration and duration risk is modeled by assuming that investors maximize Generalized Expected Discounted Utility (Dejarnette et al., 2020). Impatience plays a key role in portfolio choice. On the one hand, impatient investors find shortterm bond unattractive as low yield entails longer expected investment periods. On the other hand, impatience, not marginal utility of wealth across states, is a main driver of risk aversion in the duration domain. More impatient investors are also more averse to timing risk. The second factor dominates the first one with the result that more impatient individuals invest less in equities. I also show that investors optimally rebalance their portfolio by decreasing the equity share when wealth approaches its target.

Portfolio choice and the optimal combination of risky and safe assets have been extensively studied in the literature, starting with the Capital Asset Pricing Model (CAPM) introduced by Markowitz (1952). Contrary to the CAPM which assumes a fixed time frame, the present paper studies the twin problem of a fixed terminal wealth and uncertain time horizon. A few articles have investigated related issues. Martellini and Urošević (2006) analyze a Markowitz problem 
in which investors face an uncertain exit date. Liu and Loewenstein (2002) study an intertemporal portfolio optimization problem with an exponentially distributed time-horizon. Karatzas and Wang (2001) solve the optimal dynamic investment problem when the uncertain time horizon is a stopping time of asset price filtration. Blanchet-Scalliet et al. (2007) extend the setup to a case with a stochastically time-varying probability of exiting the market. Huang et al. (2008) adopt a worst-case Conditional Value-at-Risk approach to manage the exit date. Those articles minimize a measure of downside risk or assume mean-variance or constant relative risk aversion preferences, whereas this article stresses the importance of going beyond standard preferences in presence of timing risk. They also consider exogenous exit dates or exit strategies which depend on asset price behavior. The goal is not formulated as a specific target wealth to be met, as in this article.

The model contributes to the vast literature on dynamic portfolio choice models with a long-term focus (see Campbell and Viceira, 2002, for a survey). Studies generally find that young investors should take more risk than older investors (e.g. Bodie, Merton and Samuelson, 1991, Viceira, 2001, Cocco, Gomes and Maenhout, 2005). When wealth risk is replaced by time horizon risk, longterm investors, who set a high money target relative to current wealth, should invest more in equities than those with wealth closer to their target. Contrary to popular financial advice with a fixed selling date however, the decrease is not linear. The equity share can stay flat for a large interval of relative wealths.

The literature on attitude towards timing risk is sparse and most applications to real world problems are still to be explored. Chesson and Viscusi (2003) note that the Expected Discounting Utility model leads to a counter-intuitive preference for timing risk. Several extensions accounting for timing risk aversion have been proposed, like probability weighting (Onay and Öncüler, 2007), Epstein-Zin 
preferences (Dillenberger, Gottlieb and Ortoleva, 2019) or Generalized Expected Discounted Utility (GEDU), recently investigated in depth by Dejarnette et al. (2020). The portfolio choice model assumes GEDU preferences, which are more intuitive and tractable than Epstein-Zin preferences. The initial aim of these preferences was to distinguish the coefficient of relative risk aversion from the elasticity of intertemporal substitution in consumption. The latter is not relevant in problems in which the consumption date, not the consumption level, is uncertain. The GEDU model is also more in accordance with experimental results than the probability weighting model (Dejarnette et al., 2020).

The remainder of the paper is organized as follows. Section 2 presents basic facts about mean-variance trade-offs in the duration domain using long-term US asset returns. Section 3 proposes a simplistic theory of portfolio choice by replacing return expectation and risk in the Markowitz model by duration expectation and risk. Section 4 lays out a dynamic portfolio choice model with GEDU preferences. Section 5 simulates the model and interprets the results. Section 6 concludes.

\section{Stylized facts on investment durations}

I compare in this section duration statistical properties of two main security classes: US equities and money market securities. For equities, I use data on Standard and Poosr's (S\&P) 500 stock market index, dividends and CPI inflation rate covering the period 1871-2019 from Robert Shiller's webpage ${ }^{1}$. Since I focus

\footnotetext{
${ }^{1}$ Available at http://www.econ.yale.edu/ shiller/data.htm. Data come from Cowles (1939) for the period 1871-1925. They include all stocks listed on the New York Stock Exchange and cover between 12 (1871) and 258 (1925) value weighted securities. From 1926, the data are based on the the S\&P 90 index before 1957 and S\&P500 index provided by the Center for Research in Security Prices (CRSP). See Shiller (2005) for additional details.
} 
on medium or long-term investment objectives, monthly returns are annualized before computing the real total returns of S\&P500 stock market index.

For the market interest rate, I use short term bonds' annualized rates, also provided by Shiller's webpage on an annual basis ${ }^{2}$. It consists in the 6 -month commercial paper rate published by the Federal Reserve Board until 1997, and the 6-month certificate of deposit rate from 1997 to 2012. The series are completed until early 2020 by data from macrotrends.net. I then compute real returns thanks to Shiller's CPI inflation rates. ${ }^{3}$

For brevity, the S\&P500 stock market index is called "equities" from now on and, and US short-term bonds "bills". Let us first take the example of an investor whose initial wealth is $\$ 1$ and plans to fund a project worth $\$ 2$. Figure 1 indicates how many years are necessary to double wealth invested either in equities or bills. Unsurprisingly, time intervals shorten during equity booms, as in the 1920's or at the end of the 2000's, and lengthen during financial downturns, as in the first years of the 1930's or at the beginning of the 2000's. The figure shows wide time variations across initial investment dates. It took only 2 years to double wealth invested in equities in 1927. Two years later, the same operation required 23 years.

Time intervals for bills were quite stable until 1919 (around 16 years), then experienced a rapid increase to 33 years in 1922, a short stabilization until 1933 and a slow-moving gradual decline to a low 6 years in 1979. Time intervals rose again until 1994, which is the last investment date for which doubling wealth were possible before the series' end in 2019. Bills' yields seem especially volatile in periods of low returns during which even small variations entail large swings

\footnotetext{
${ }^{2}$ See Chapter 26 of Shiller (1989) and Shiller (2015) for more details.

${ }^{3}$ Treasury bills would heave provided a better proxy for the riskless return than commercial papers and certificate of deposits but were not available before 1920 .
} 
in duration. This was the case between 1920 and 1940 during which average yearly return was low $(1.7 \%)$.

I next quantify how the two assets compare in terms of mean duration and time horizon risk. Table 1 presents summary statistics on time lengths required to accumulate various final amounts of wealth starting with $\$ 1$. Results are summarized in five stylized facts.

Fact 1. Mean duration is approximately $60 \%$ longer with bills.

The "bill delay premium" (see Table 1) is the average additional delay expressed in percentage for investors to meet their wealth target when they invest in bills rather than in equities. The gap is significant and may deter impatient investors from investing in low-yield short-term bonds. Fact 1 is a consequence of the historical equity risk premium. In the data, equity real returns are on average $3.7 \%$ higher than bills' returns.

Fact 2. Time horizon risk increases with target wealth.

The higher the wealth target relative to initial investment the more uncertain the investment horizon, both with equities and bills. Fact 2 parallels the wellknown fact that final wealth risk increases with horizon.

Fact 3. Time horizon risk is higher for bills than equities.

Bills perform worse than equities with respect to both mean duration and standard deviation, whatever target wealth. Fact 3 does not accord well with mean variance portfolio theory according to which investors accept to buy high risk assets in exchange of better expected returns. The classical mean variance trade-off faced by target date investors does not seem to be a trade-off for target wealth investors (more on this issue next section).

Bills' underperformance is visually confirmed in Figure 1. The two assets' 
risk is of different types however. Bills display extremely low frequency variations with only one peak over the whole period, whereas equity's risk is mainly driven by the business cycle.

Fact 4 . Time horizon risk is positively skewed.

Duration skewness matters for time prudent investors. Ebert (2018) shows in experiment that a large majority of subjects dislike positive skewness, a situation which appears when large durations are more likely than small ones. Duration skewness is positive and decreases with target wealth both for equities and bills. Since skewness is higher for bills than for equities and for all target wealths, bills are therefore riskier on this dimension as well.

Fact 5. Duration correlations between the two assets are negative.

Whatever target wealth levels, longer than average investment horizon for one asset tends to be associated with shorter than average horizon for the other. Correlations increase with target wealth, suggesting significant diversification gains in mitigating duration risks (see next section), especially for high target wealth investors. Negative correlations of durations mirror negative correlations between equities' and bills' yearly returns ( -0.129 over the whole period).

We remark that statistics on returns do not map exactly into statistics on durations. Mean durations, duration variance and duration skewness depend on return statistics but compounded over variable investment periods. Return risks are for instance traditionally compared by computing return variance over a fixed time frame. Since bills entail on average longer investment periods, duration variances in Fact 3 are computed over longer sequences of returns than equities. 


\section{Mean variance approach}

The textbook mean variance portfolio choice model is a useful benchmark to start with. It is analytically simple, delivers deep intuitions about risk-return trade-offs or diversification, and allows insightful graphical interpretations. The original model is framed in terms of final wealth but can be recast in terms of durations where "mean" refers to mean duration, "variance" to duration variance and return risk diversification to "horizon risk diversification".

Let us assume that investors care only about expected duration $E(t)$ and duration standard deviation $\sigma(t)$ with $t$ the time length necessary to attain a given target wealth. Investors' utility function is $U(E(t), \sigma(t))$ with $U_{1}>0$ (they prefer short durations) and $U_{2}<0$ (they dislike duration spreads around mean). I also assume the absence of a riskless asset and the stationarity of the return process of the two assets. In particular, I make the (strong) assumption that the means and variance-covariance matrix of annual real returns for bills and stocks from 1871 to 2019 represent the distribution of future returns.

Figure 2 describes how duration first and second moments change when the mix between the two assets varies. Duration is defined as the time length required for wealth to double. The curve connects feasible portfolios in the mean/standard deviation space when the equity share varies from 0 to $100 \%$ by steps of $5 \%$. For every equity share, rolling window statistics on historical durations are computed over the period 1871-2019.

The curve is ellipse-shaped, as in classical Markowitz portfolio theory. The bold part of the portfolio curve is equivalent to Markowitz's efficient frontier in the duration domain. It excludes the gray upper arc rejected by timing risk averse investors. The minimum variance portfolio is composed for two thirds of bills (65\%) and one third of equities. As already noted, the $100 \%$ equity 
portfolio dominates the $100 \%$ bill portfolio both in terms of expected duration and standard deviation. This does not mean however that the optimal portfolio should not include bills. Table 1 shows strong negative correlations between equities' and bills' durations, indicating that investors may achieve substantial horizon risk diversification. Starting from the all-equity portfolio, for which duration standard deviation is 6.1 , reducing equity share decreases horizon risk by a significant margin, down to 3.7 if investors buy the minimum variance portfolio.

Efficient portfolios involve a substantial share of equities with a minimum of $35 \%$. The figure indicates as an illustration a possible optimal portfolio $\mathrm{P}$, composed of $55 \%$ of equities and for which investors' indifference curve (IC) is tangent to the portfolio curve. The efficient frontier looks relatively flat beyond $\mathrm{P}$, which suggests that only investors sufficiently tolerant to timing risk would be willing to invest a larger fraction of their wealth in equities.

Figure 3 plots feasible portfolios in the mean/standard deviation space for target wealths ranging from 1.5 to 4 , stating with $\$ 1$. Mean durations and duration risks are both increasing with target wealth, but mean duration increases visually faster than duration risk. Long-term investors (with high target wealth) face higher duration risk than short-term investors but only by a modest margin.

Table 2 illustrates the point by focusing on minimum variance portfolios. Those portfolios are an interesting reference as all risk averse investors choose a higher equity share. Duration standard deviation is barely increasing with target wealth. Switching from a target wealth of 1.5 to 4 corresponds to a $166 \%$ money goal increase and a $188 \%$ increase of mean duration (from 8.5 to 24.1 years), but a modest $25 \%$ increase in duration standard deviation (from 3.2 to 4.0). In accordance with this pattern, minimum variance equity share increases with target wealth, starting from $32 \%$ for a target wealth of 1.5 , to $47 \%$ for a 
target wealth of 4 . Those results suggest that the optimal equity share is likely to decrease with distance to target wealth, a property explored next section.

Overall, the mean variance approach shows strong horizon risk diversification benefits, points to significant shares of equities and suggests large time diversification gains associated with higher wealth target and longer investment time horizon.

\section{Portfolio choice with Generalized Preferences}

The mean-variance portfolio choice model catches basic intuitions about efficient portfolios in presence of duration risk. Like the original Markowitz model however, it is static (investors care only about risks to wealth one period ahead) and assumes ad hoc preferences. The next sections investigate an intertemporal model of portfolio choice with better founded preferences.

\subsection{Generalized Expected Discounted Utility}

Let us define the set of dates $T=\{0,1, \ldots, \tau\}$. Intertemporal utility is defined over consumption streams $C=(c(0), c(1), \ldots, c(\tau))$ :

$$
U(C)=\sum_{T} D(t) u(c(t))
$$

with $u$ a strictly increasing and continuous function from $[\underline{c}, \bar{c}] \subset \mathbb{R}_{+}$to $\mathbb{R}_{+}$and $D$ a strictly decreasing function from $T$ to $[0,1]$.

Consumption risks are represented, without loss of generality, as risks over consumption streams $C$, which in turn makes intertemporal utility uncertain. Generalized Expected Discounted Utility (GEDU) preferences ${ }^{4}$ assumes that in-

\footnotetext{
${ }^{4}$ The representation is an application of the multi-attribute function of Kihlstrom and Mir-
} 
dividuals depart from risk neutrality when dealing with intertemporal utility uncertainty, and maximize $\mathbb{E} \phi(U(C))$, where $\phi$ is a strictly increasing function from $U(C)$ to $\mathbb{R}$.

The GEDU representation is useful to disentangle attitude towards intertemporal consumption smoothing, captured by curvature of $u$, from attitude towards date $t$ consumption risk, captured by curvature of $\phi \circ(D(t) u)$. The shape of the discount function $D$, which governs impatience, also affects preferences when the consumption date is uncertain through the curvature of $\phi \circ(D u(w))$, with $w$ a fixed consumption level. The fact that $\phi$ influences both aversion to static consumption risk and aversion to consumption timing risk is in accordance with experimental evidence (see Dejarnette et al., 2020).

GEDU preferences are particularly fitted to study how individual value consumption date risk. In the EDU model (or the GEDU model with $\phi$ affine), $D(t)$ governs both impatience and attitude towards timing risk. There is no compelling reason why preferences in two distinct domains should be determined by the same functional. In fact, EDU implies a counter-intuitive preference for random timing under the weak assumptions that $D(t)$ is decreasing and convex. Dejarnette et al. (2020) find in experiment that the vast majority of subjects are averse toward timing risk, i.e. prefer a sure delivery date than a mean preserving random date, which contradicts the EDU model.

\subsection{Investment strategy}

There are two assets in the economy: equities, which period $s$ return is $R_{s}^{r}$ and fixed income assets, which return is $R_{s}^{f}$. Given a temporal sequence of equity man (1974) to the context of time. The term GEDU has been coined by Dejarnette et al. (2020). See also Dillenberger, Gottlieb and Ortoleva (2019). 
shares $\left(\alpha_{0}, \alpha_{1}, \ldots, \alpha_{t-1}\right)$, portfolio's cumulative return factor between dates 0 and $t$ is:

$$
R_{0 \rightarrow t}\left(\alpha_{0}, \alpha_{1}, \ldots, \alpha_{t-1}\right)=\prod_{s=0}^{t-1}\left(\alpha_{s} R_{s}^{r}+\left(1-\alpha_{s}\right) R_{s}^{f}\right)
$$

The model allows investors to dynamically rebalance their portfolio. They choose $\alpha_{s}$ at the beginning of every investment period $s$ and anticipate their portfolio will be optimally rebalanced in future dates. I abstract from transactions costs and forbid borrowing or short sales. I make the simplifying assumption that asset returns are independently distributed over time. Bills' and equity's real returns are actually serially correlated in the data ${ }^{5}$, which could make possible to predict future return based on past returns, and to condition equity share on this information. How does return predictability affect optimal portfolio choice would deserve a separate extension which is beyond the scope of this article. The assumption of serial independence does not mean that the set of investment opportunities is the same every period however. As cumulated wealth gets closer to target wealth, the set of investment opportunities may vary, which could affect the optimal equity share. ${ }^{6}$

Investors make a one-time contribution $w<1$ at date 0 and wait until their wealth attains $\$ 1$. They first choose the equity share $\alpha_{0}$ which maximizes their expected discounted utility of wealth:

$$
\max _{\alpha_{0}} \sum_{t=0}^{\tau} \pi_{t}\left(\alpha_{0}, \alpha_{1}^{*}, \ldots, \alpha_{t-1}^{*}\right) \phi(D(t) u(1))
$$

where $\pi_{t}($.$) is the probability that accumulated wealth reaches \$ 1$ at date $t$ for

\footnotetext{
${ }^{5}$ Many studies find that expected stock returns are countercyclical. See e.g. Fama and French (1989), Ferson and Harvey (1991), Harrison and Zhang (1999), or Golez and Koudijs (2018).

${ }^{6} \mathrm{~A}$ similar reasoning holds for target date strategies. As final date approaches, the distribution of cumulated final return changes, and so does optimal equity share. The equity share remains constant only for constant relative risk aversion investors with a fixed interest rate (Samuelson, 1969, Merton, 1969).
} 
the first time:

$$
\begin{array}{r}
\pi_{t}\left(\alpha_{0}, \alpha_{1}, \ldots, \alpha_{t-1}\right)=\operatorname{Prob}\left[\left(R_{0 \rightarrow 1}\left(\alpha_{0}\right) w<1\right) \bigcap\left(R_{0 \rightarrow 2}\left(\alpha_{0}, \alpha_{1}\right) w<1\right) \bigcap \ldots\right. \\
\left.\bigcap\left(R_{0 \rightarrow t-1}\left(\alpha_{0}, \alpha_{1}, \ldots, \alpha_{t-2}\right) w<1\right) \bigcap\left(R_{0 \rightarrow t}\left(\alpha_{0}, \alpha_{1}, \ldots, \alpha_{t-1}\right) w \geq 1\right)\right]
\end{array}
$$

Conditional on target wealth $w$ still to be reached, date $s>1$ optimal equity shares are chosen the same way $s$ periods forward.

Program (3) ignores the possibility that investors may outreach their target and eventually consume more than $\$ 1$. For now, I will assume that the investment unit period is sufficiently short so that the assumption of constant utility may be acceptable. This issue is more rigorously addressed in the simulation method presented in Appendix by introducing fractional investment dates.

\section{Simulated Portfolio choice}

This section presents how the portfolio choice model is simulated based on the dataset used in Sections 2 and 3.

\section{$5.1 \quad$ Functionals}

I assume common functionals for $\phi$ and $D$. For riskless intertemporal trade-offs, investors are exponential discounter: $D(t)=\beta^{t}$. For intertemporal utility tradeoffs, $\phi$ takes a constant relative risk aversion form with risk aversion parameter $\gamma>0$ :

$$
\phi(U)=\frac{U^{1-\gamma}}{1-\gamma}
$$

for $\gamma \neq 1$, and $\phi(U)=\ln (U)$ for $\gamma=1$. The target wealth strategy (3) writes :

$$
\max _{\alpha_{0}} \sum_{t=0}^{\tau} \pi_{t}\left(\alpha_{0}, \alpha_{1}^{*}, \ldots, \alpha_{t-1}^{*}\right) \frac{\beta^{t(1-\gamma)}}{1-\gamma}
$$


with normalization $u(1)=1$ and $\pi_{t}($.$) defined in (4). In the case \gamma=1$, investors are risk neutral with respect to consumption timing, as can be seen from their maximization program:

$$
\max _{\alpha_{0}} \ln (\beta) \sum_{t=0}^{\tau} \pi_{t}\left(\alpha_{0}, \alpha_{1}^{*}, \ldots, \alpha_{t-1}^{*}\right) t
$$

Impatient investors $(\beta<1$ or $\ln (\beta)<0)$ minimize expected duration regardless of duration's dispersion. If $\phi$ is more concave than $\log (\gamma<1)^{7}$, investors are timing risk averse (Dejarnette et al., 2020). They seek mean preserving date randomization if $\phi$ is more concave than $\log (\gamma>1)$.

Because the only source of uncertainty is the consumption date, portfolio choice does not depend on static risk aversion captured by period utility $u$. Moreover, under the assumption that financial returns are serially uncorrelated, it does not depend on past returns either. A distance effect, expressed as a function of the remaining gap between current and target wealth, may nevertheless exist. Mean-risk trade-off for consumption date depends on how far current wealth is from its target. The optimal target wealth portfolio choice is a timeless function $\alpha(x)$ from $\left[w_{0}, 1\right)$ to $[0,1]$ which gives for each current wealth $x$ the optimal portfolio's equity share. The simulation method is presented in Appendix.

\subsection{Calibration}

Two behavioral parameters are assigned numerical values. The discount factor is set to 0.953 to match the average real annualized riskless rate of $4.88 \%$ computed from Shiller's dataset over the period 1871-2019.

The relative risk aversion coefficient (RRAC) $\gamma$ drives aversion toward intertemporal utility risk. Although possible values for the RRAC in the context

\footnotetext{
${ }^{7}$ The function $\phi$ is more concave/convex than $\log$ if $\phi=f \circ \ln$ for some concave/convex $f$.
} 
of static consumption risks are extensively documented, this is not the case in the domain of intertemporal utility risk. In accordance with experimental results of Dejarnette et al. (2020), I restrict the analysis to the case of timing risk aversion $(\gamma \geq 1)$ and select a broad range of values between 1 and 31 .

\subsection{Results}

Figure 4 shows optimal equity shares given relative distance between current and target wealth. The stronger the risk aversion parameter $\gamma$, the smaller the equity share. Risk neutral investors characterized by $\gamma=1$ stay close to $100 \%$ for a large wealth interval. In contrast, investors with strong aversion to intertemporal utility risk $(\gamma \geq 6)$ are heavily invested in bills. Investors with intermediate level of risk aversion ( $\gamma$ between 2 and 5 ) choose a more balanced portfolio.

In addition, the equity share substantially varies with relative distance to target wealth, which supports the existence of a distance effect, reminiscent of the time horizon effects in target date strategies (Barberis, 2000). Investors reduce their equity share when their accumulated wealth approaches the target, but in a non linear manner. The equity share starts from $100 \%$ for moderately risk averse investors ( $\gamma$ between 1 and 3) far from their target. Equity shares plateau over a wide range of wealths for all risk aversion levels, before converging to zero close to the target. The convergence to zero equity is explained by the fact that investors bear the downside cost but do not benefit from the upside beyond the wealth target. Intuitively, investing in equity near the target is much like being the owner of a debt contract in an equity fund.

The influence of the discount factor on portfolio choice is illustrated in Figure 5 where $\gamma$ is set to 11 . The time discounting parameter $\beta$ takes several values ranging from 0.900 to 0.999 . We observe a similar pattern of risk profiles with 
a broad plateau before a convergence to zero equity. The less impatient, the more willing investors are to invest in risky assets. Investors close to time neutrality $(\beta=0.999)$ invest near $100 \%$ of their wealth in equities before gradually disinvesting. More impatient investors invest modest amounts in equities. To understand why, recall that impatient investors would like to consume sooner than later. This fosters the demand for equities which allow shorter delays on average than bills. However, impatience also makes investors more risk averse in presence of uncertainty about the consumption date. The second effect dominates the first one and makes impatient investors reluctant to invest in equities.

\section{Conclusion}

Many households pursue a personal goal when they invest, like buying a house or a car, and doing so, target a final wealth. This paper studies the case in which investors fully commit to their money goal and face an uncertain investment time horizon. Several interesting results emerge, based on US long-term return data. First, fixed income assets do not appear to be less risky than equities in the duration domain. Since fixed income assets have low returns, small variations may trigger large and lasting swings in durations. Second, a simple CAPM-like model of portfolio choice graphically shows how duration risk can be substantially reduced by adding a significant share of equities in the portfolio. This illustrates another benefit of portfolio diversification beyond its well known ability to reduce return risk. Third, investors stay away from equities out of risk aversion, impatience or a combination of the two. Fourth, the optimal risk management strategy derived from a dynamic model of portfolio allocation consists in decreasing the equity share with relative distance to target wealth. The decrease is non-linear with a broad intermediate wealth range over which the eq- 
uity share remains approximately constant. Those results provide a useful guide to financial planners who counsel households who pursue a money goal. From a regulatory perspective, the risk profiling questionnaire should specifically assess investor's willingness to take timing risk and their propensity to wait, besides their tolerance to financial risk.

Several extensions of this study would be worth exploring. In the CAPM-like model, it would be interesting to add additional assets, like bonds or equities sorted by book-to-market or size. A risk-free rate could also be introduced. Investigating the issues of the existence of a market portfolio and a two-fund separation theorem would constitute an important avenue for future research. Price multiples such as the dividend-to-price ratio predict future return (e.g. Golez and Koudijs, 2018) but could also predict future investment durations. It would be interesting in the dynamic portfolio model to condition the equity share upon not only the relative distance to target wealth, but also a well-chosen financial ratio.

\section{References}

Barberis N. (2000) "Investing for the long run when returns are predictable" Journal of Finance 55 (1), 225-264.

Blanchet-Scalliet C., N. El Karoui, M. Jeanblanc and L. Martellini (2007) "Optimal investment and consumption decisions when time horizon is uncertain", Journal of Mathematical Economics

Bodie Z., R. C. Merton and W. Samuelson (1991) "Labor Supply Flexibility and Portfolio Choice in a Life Cycle Model" Journal of Economic Dynamics and Control, 16, 427-49. 
Brennan M. J., Eduardo S. S., and R. Lagnado (1997) "Strategic Asset Allocation" Journal of Economic Dynamics and Control, 21, 1377-1403.

Campbell J. Y., and L. M. Viceira, Strategic Asset Allocation: Portfolio Choice for Long-Term Investors. Oxford, UK: Oxford University Press 2002.

Chesson H.W. and W.K. Viscusi (2003) "Commonalities in Time and Ambiguity Aversion for Long-Term Risks" Theory and Decision, 54, 57-71.

Cocco J. F., F. J. Gomes and P. J. Maenhout, (2005) "Consumption and portfolio choice over the life cycle", Review of Financial Studies, 18, 491-533.

Cowles A. "Common stock indices, 1871-1937" Cowles Commission for Research in Economics. Monograph no. 3. Principia Press, Bloomington, Inc. 1939.

Dejarnette P., Dillenberger D., Gottlieb D. and P. Ortoleva (2020) "Time Lotteries and Stochastic Impatience" Econometrica, 88 (2), 619-56.

Dillenberger D., Gottlieb D. and P. Ortoleva (2019) "Stochastic Impatience and the Separation of Time and Risk Preferences", working paper.

Ebert S. (2018) "Prudent Discounting: Experimental Evidence on HigherOrder Time Risk Preferences", working paper.

Epstein L. and S. Zin (1989) "Substitution, risk aversion, and the temporal behavior of consumption and asset returns: A theoretical framework" Econometrica, 57, 937-969.

Fama E. F. and K. R. French (1989) "Business Conditions and Expected Returns on Stocks and Bonds" Journal of Financial Economics, 25, 23-49.

Ferson W. E. and C. R. Harvey (1991) "The Variation of Economic Risk Premiums" Journal of Political Economy, 99, 385-415. 
Harrison P. and H. H. Zhang (1999) "An Investigation of the Risk and Return Relation at Long Horizons" Review of Economics and Statistics, 81, 399-408.

Golez B. and P. Koudijs (2018) "Four Centuries of Return Predictability" Journal of Financial Economics, 127, 248-263.

Huang D., S. Zhu, F. J. Fabozzi and M. Fukushima (2008) "Portfolio selection with uncertain exit time: A robust CVaR approach" Journal of Economic Dynamics and Control, 32 (2),594-623.

Karatzas I. and H. Wang (2001) "Utility maximization with discretionary stopping", SIAM Journal on Control \& Optimization, 39, 306-329.

Kihlstrom R. E. and L. J. Mirman (1974) "Risk aversion with many commodities" Journal of Economic Theory, 8, 361-388.

Liu H. and M. Loewenstein (2002) "Optimal portfolio selection with transaction costs and finite horizons, Review of Financial Studies, 15, 3, 805-835.

Markowitz H. M. (1952) "Portfolio Selection" Journal of Finance, 7 (1) 77-91.

Martellini L. and B. Urošević (2006) "Static Mean-Variance Analysis with Uncertain Time Horizon", Management Science 52:6, 955-964.

Merton R. C. (1969) "Lifetime Portfolio Selection under Uncertainty: The Continuous- Time Case", Review of Economics and Statistics, 51, 247-257.

Onay S. and A. Öncüler (2007) "Intertemporal choice under timing risk: An experimental approach" Journal of Risk and Uncertainty, 34, 99-121.

Ortu F., A. Tamoni and C. Tebaldi (2013) "Long-run risk and the persistence of consumption shocks" Review of Financial Studies, 26, 2876-2915.

Samuelson, P. A. (1969) "Lifetime Portfolio Selection By Dynamic Stochastic Programming" Review of Economics and Statistics, 51, 239-246. 
Shiller R. Market Volatility, MIT Press 1989.

Shiller R. Irrational Exuberance, Princeton 2015.

Viceira L. M. (2001) "Optimal Portfolio Choice for Long-Horizon Investors with Nontradable Labor Income" Journal of Finance, 56, 433-470.

Weil P. (1989) "The equity premium puzzle and the riskfree rate puzzle" Journal of Monetary Economics 24, 401-421.

\section{Appendix}

\section{Simulation method for target wealth strategy}

To find the optimal equity share $\alpha(x)$, conditional on current wealth $x$, I define $V(x)$, the expected intertemporal utility for wealth $x$. Let $f(R(\alpha))$ be the density function of investor's yearly portfolio return conditional on equity share $\alpha . V(x)$ is defined recursively as the expected discounted value of capitalized wealth one period ahead:

$$
V(x)=\max _{\alpha} \int_{\underline{R}}^{\bar{R}} \beta^{1-\gamma} V(R(\alpha) x) f(R(\alpha)) d R(\alpha)
$$

where $\underline{R}$ and $\bar{R}$ denote minimum and maximum portfolio returns. Target wealth's value is $V(1)=1 /(1-\gamma)$. Since last period compound wealth may actually be greater than target wealth, we need to adjust at the margin the consumption date. The more wealth in excess at date $t$, the earlier investors can sell and consume before $t$, but still after $t-1$ since by assumption $x<1$. Excess wealth ratio is defined as:

$$
\varepsilon(\alpha)=\frac{R(\alpha) x-1}{R(\alpha) x-x} \in[0,1)
$$


The date advancement is assumed to be proportional to excess wealth ratio:

$$
V(R(\alpha) x)=\beta^{-(1-\gamma) \varepsilon(\alpha)} V(1)
$$

As an illustration, suppose that last period return $R(\alpha) x-x$ is $\$ 0.036$ from which excess wealth is $R(\alpha) x-1=\$ 0.009$. Excess wealth ratio is $\varepsilon(\alpha)=0.25$. Under the proportionality assumption, consumption takes place 3 months in advance of date $t$.

Current wealth $x$ is discretized over a fine and equally spaced grid $W=$ $\left[w_{0}, w_{0}+\epsilon, \ldots, 1-\epsilon, 1\right]$ where $\epsilon$ is the unit interval length and $w_{0}$ is wealth's lower bound. The value function (6) is discretized and becomes:

$$
V(x)=\max _{\alpha} \sum_{y \in W} \operatorname{Prob}\left(R_{s}(\alpha) x=y\right) \beta^{1-\gamma} V(y)
$$

with $V(y)$ defined by (7) if wealth overshoots its target $\left(y=R_{s}(\alpha) x \geq 1\right)$.

The maximization problem is solved downward, starting from $x=1-\epsilon$. For any wealth level $x$, most next period values $V(y)$ satisfy $y=R_{s}(\alpha) x>x$ and have been estimated in earlier steps of the downward simulation. Values $V(y)$ satisfying $y=R_{s}(\alpha) x>1$ are determined by (7). In periods with negative return $\left(y=R_{s}(\alpha) x<x\right), V(y)$ is unknown in the first estimation round. It is approximated by solving a simpler portfolio choice problem in which the equity share depends on current wealth $x$ but remains constant in subsequent periods.

With estimated values $V(y)$, the maximization problem (8) is solved by computing the sample mean:

$$
V(x)=\max _{\alpha} \frac{1}{N} \sum_{h=1}^{N} \beta^{1-\gamma} V\left(R_{h}(\alpha) x\right)
$$

with $R_{h}(\alpha)=\alpha R_{h}^{r}+(1-\alpha) R_{h}^{f}$ year $h$ portfolio return. The optimal equity share $\alpha(x)$ maximizes $V(x)$ over $A$ for every $x$ over $W$. Because $V(y)$ is only roughly 
estimated in the fist round when $y<x$, several rounds are needed until $V(y)$ converges to stable values.

In simulations, the space of current wealth $W$ contains 800 values with $w_{0}=$ 0.2 and $\epsilon=0.001$. When $x$ is close to the lower bound $w_{0}$, next period wealth $y=R_{h}(\alpha) x$ can sometimes be lower than $w_{0}$. In those cases $V(y)$ is artificially set to $V\left(w_{0}\right)$. Because downside risk is muted, this convention biases $\alpha(x)$ upward for $x$ in the neighborhood of $w_{0}$. Extensive testing shows that discarding all equity shares for $x \in[0.2,0.25)$ eliminates the bias from the result with a good safety margin. 
Figure 1: Number of years to double wealth, US 1871-2019

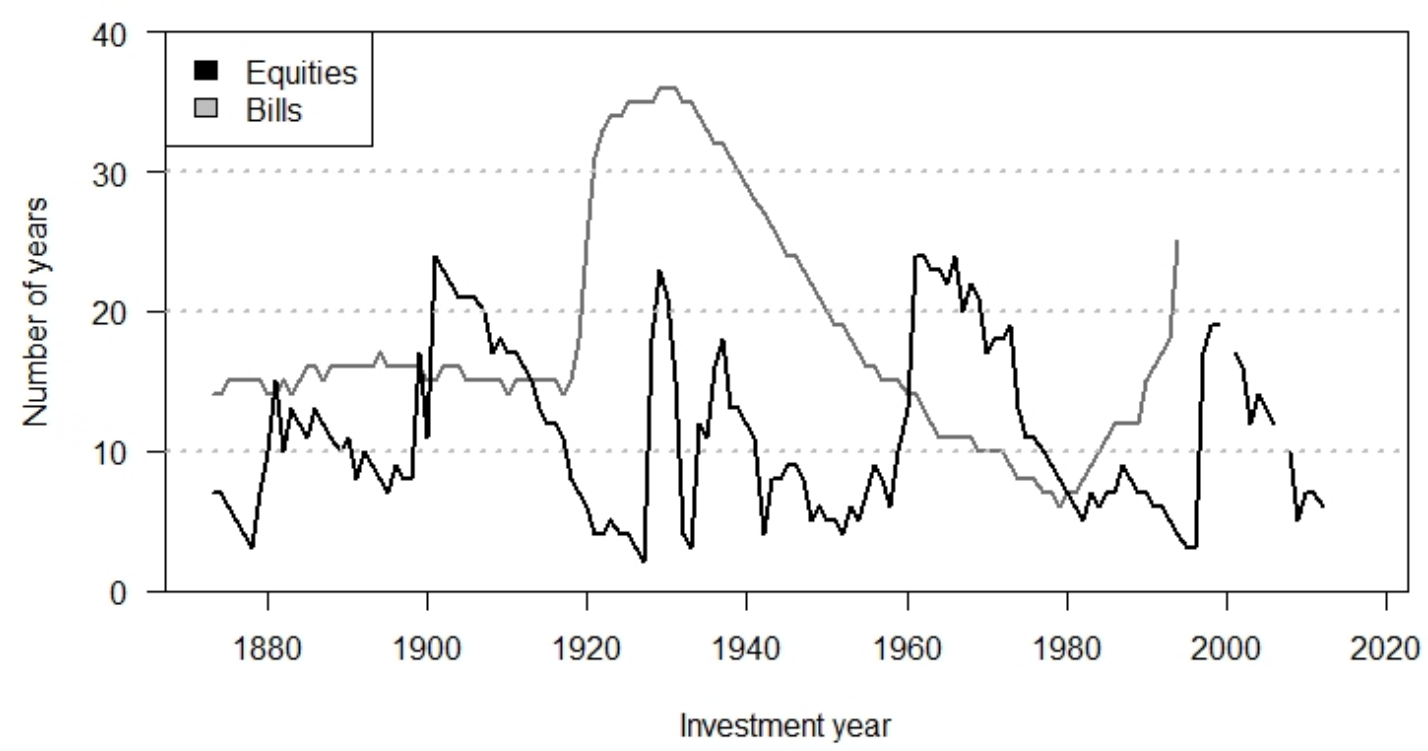

Notes. The graphic indicates how many years are necessary to double initial wealth by investing either in equities or bills for stating years beginning in 1871 and ending in 2015. Some points are missing after 2000 as wealth does not double before the last year in the dataset. 
Table 1: Summary statistics for equity and bills, US 1871-2019

\begin{tabular}{lccccccc}
\hline Target wealth for $\$ 1$ invested & 1.25 & 1.5 & 2 & 2.5 & 3 & 3.5 & 4 \\
\hline & Equities & & & & & \\
\hline Mean duration & 4.5 & 7.3 & 11.2 & 13.8 & 16.3 & 18.6 & 20.4 \\
Duration standard deviation & 4.0 & 5.1 & 6.0 & 6.3 & 6.5 & 7.0 & 6.9 \\
Duration skewness & 1.6 & 1.07 & 0.60 & 0.47 & 0.31 & 0.20 & 0.02 \\
Number of rolling windows & 147 & 142 & 128 & 126 & 125 & 124 & 124 \\
\hline & & Bills & & & & & \\
\hline Mean duration & 7.1 & 11.5 & 18.0 & 22.8 & 26.7 & 30.0 & 32.9 \\
Duration standard deviation & 4.7 & 6.3 & 8.1 & 9.0 & 9.8 & 10.3 & 10.9 \\
Duration skewness & 1.7 & 1.37 & 0.98 & 0.68 & 0.45 & 0.26 & 0.12 \\
Number of rolling windows & 136 & 128 & 123 & 118 & 115 & 113 & 113 \\
\hline Bill delay premium (\%) & 58 & 58 & 61 & 65 & 64 & 61 & 61 \\
\hline
\end{tabular}

Notes. The table presents statistics about durations required to convert $\$ 1$ into a final wealth ranging from $\$ 1.25$ to $\$ 4$. The bill delay premium is the additional delay expressed in percentage imposed by bills compared to equities. As durations vary across assets, duration correlations are computed for a common investment starting period. 
Figure 2: Duration mean variance frontier and optimal portfolio

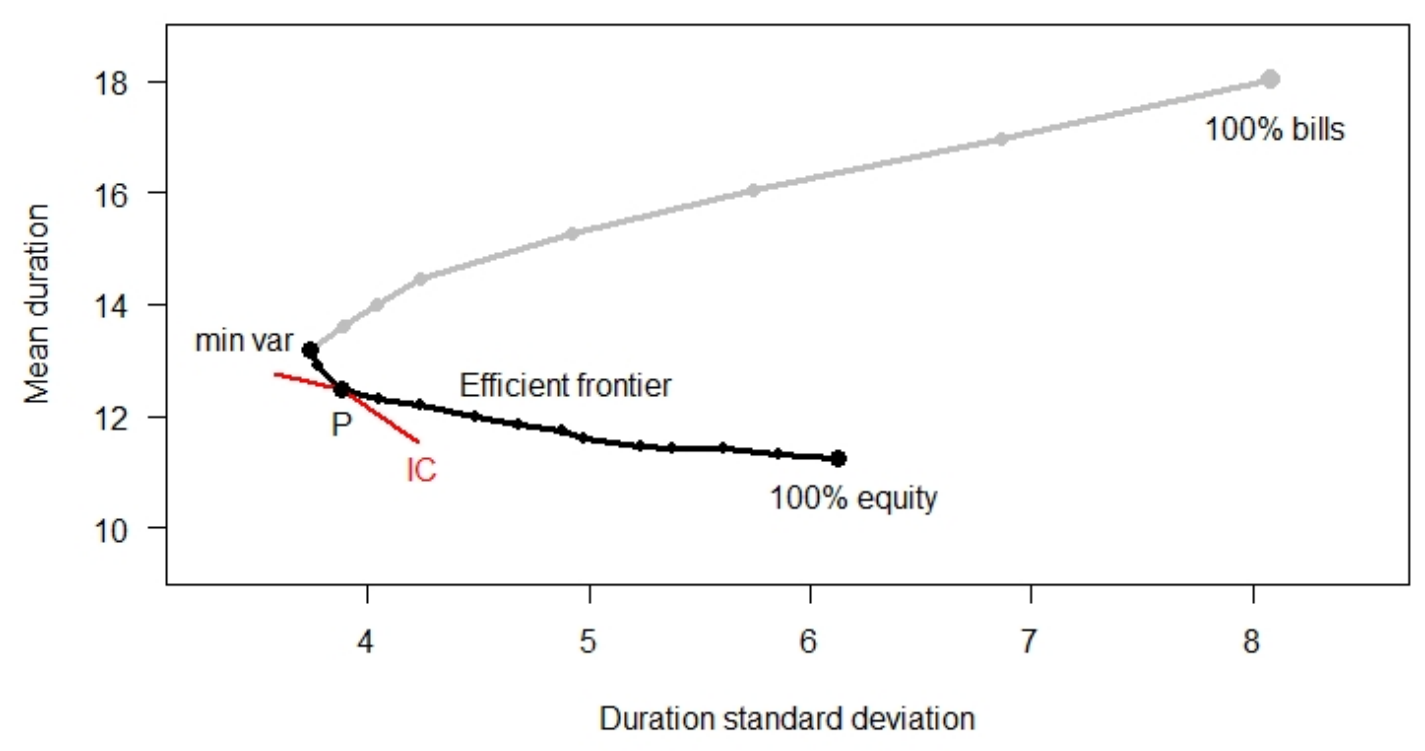

Notes. The graphic indicates feasible portfolios in the duration mean variance space for equity shares varying from 0 to $100 \%$ by step of $5 \%$. Computation of durations needed to double wealth is based on US data, 1871-2019. The efficient frontier holds for investors preferring shorter durations and lower duration risk. Portfolio 'min var', the minimum variance portfolio, is composed of $55 \%$ of equity. $\mathrm{P}$, a possible optimal portfolio given indifference curve IC, has $65 \%$ of equity. 
Figure 3: Duration mean variance curves for various target wealths

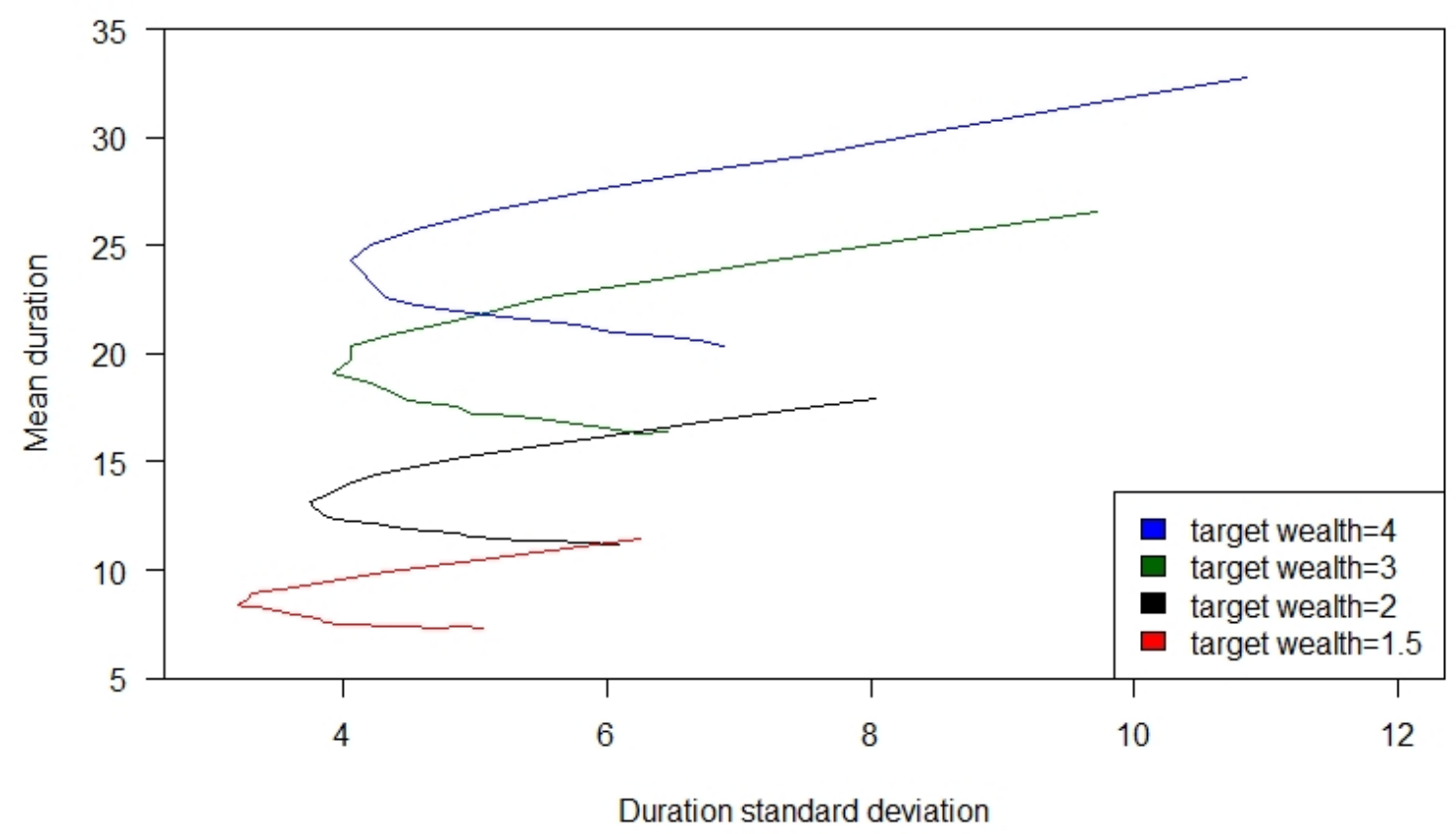

Notes. The graphic indicates feasible portfolios in the duration mean variance space for equity shares varying from 0 to $100 \%$ by step of $5 \%$ and various target wealths, starting with $\$ 1$. Computation of durations is based on US data, 18712019 . 
Table 2: Summary statistics for minimum variance portfolios, US 1871-2019

\begin{tabular}{lcccccc}
\hline Target wealth for $\$ 1$ invested & 1.5 & 2 & 2.5 & 3 & 3.5 & 4 \\
\hline Mean duration & 8.5 & 12.9 & 16.8 & 19.3 & 21.9 & 24.1 \\
Duration standard deviation & 3.2 & 3.7 & 3.9 & 3.9 & 4.1 & 4.0 \\
Share of equities $(\%)$ & 32 & 38 & 36 & 44 & 44 & 47 \\
\hline
\end{tabular}

Notes. The table presents statistics and equity shares of minimum variance portfolios for target wealths ranging from $\$ 1.5$ to $\$ 4$, starting with $\$ 1$. 
Figure 4: Optimal equity share as a function of distance to target wealth and risk aversion

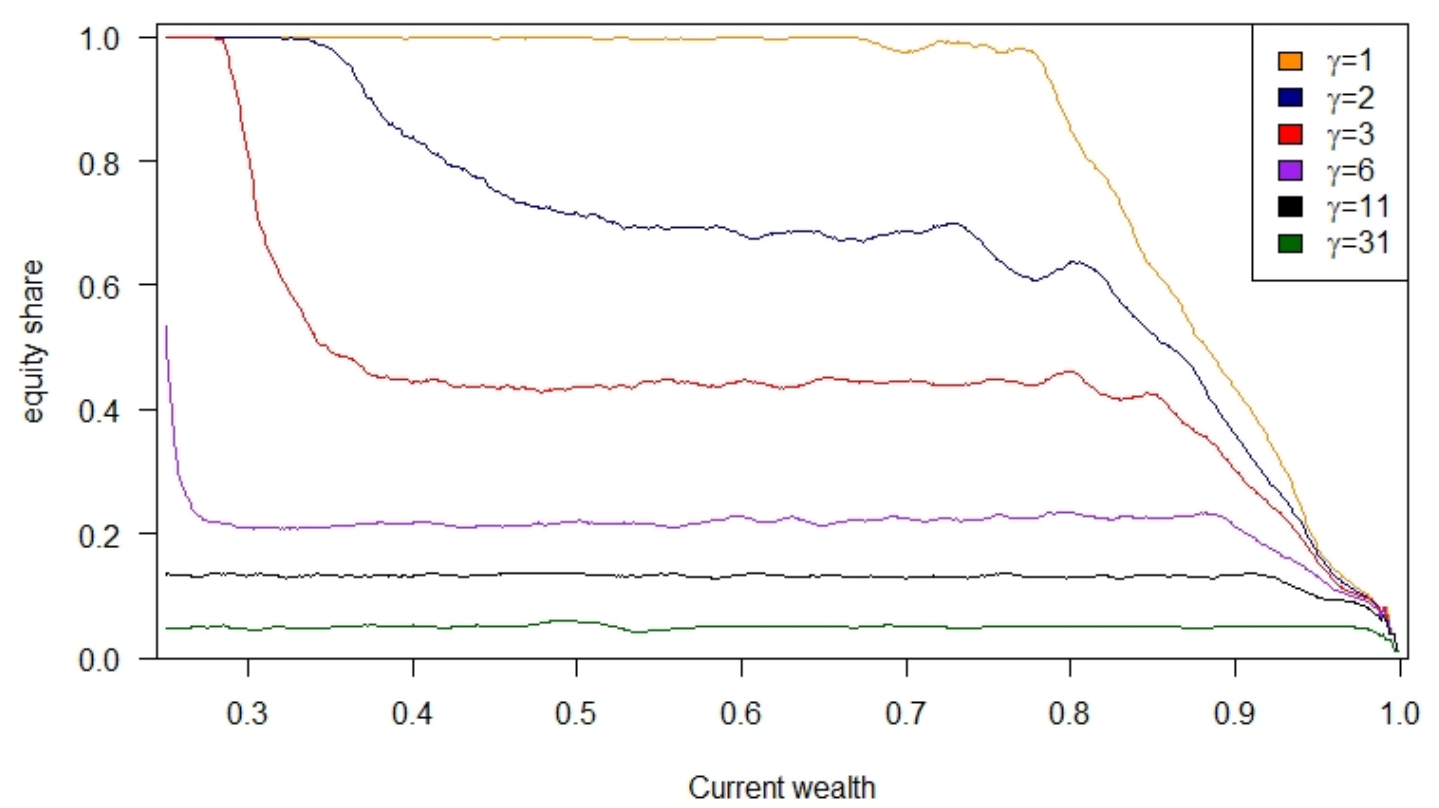

Notes. The graphic indicates optimal equity shares in function of the relative gap between current and target wealth. Wealth in horizontal axis goes from $25 \%$ to $100 \%$ of target wealth. The discount factor is $\beta=0.953$. The relative risk aversion coefficient $\gamma$ takes values ranging from 1 to 31. Simulated shares are affected by small high-frequency noise, which is smoothed out by plotting a centered moving average over a narrow rolling wealth interval of 0.02 . 
Figure 5: Optimal equity share as a function of distance to target wealth and time discounting

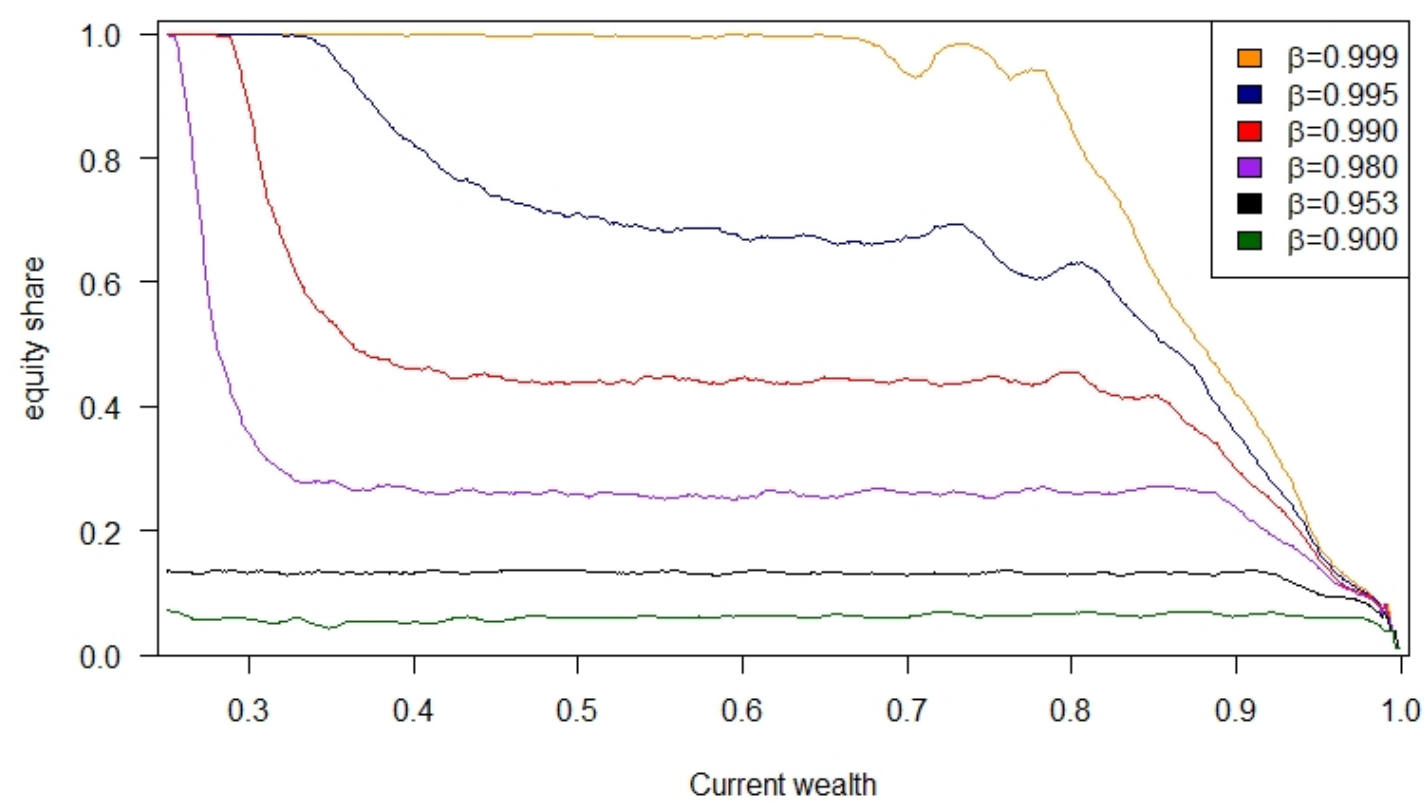

Notes. The graph indicates optimal equity shares in function of the relative gap between current and target wealth. Wealth in horizontal axis goes from $25 \%$ to $100 \%$ of target wealth. The risk aversion coefficient is $\gamma=11$. The annual time discounting coefficient $\beta$ takes values ranging from 0.900 to 0.999 . Simulated shares are affected by small high-frequency noise, which is smoothed out by plotting a centered moving average over a narrow rolling wealth interval of 0.02 . 